\title{
Map, Tables, and Figures
}

MAP

Map of Pakistan

xxvi

\section{TABLES}

5.1 Pakistan Nuclear Infrastructure

7.1 Development of Enriched Uranium Route

9.1 Bomb Design

10.1 Development of Plutonium Route 203

12.1 Missile Inventory 250

\section{FIGURES}

17.1 Organizational Chart: Combat Development Directorate (CD Directorate, 1985-1998)

17.2 Organization of Strategic Plans Division (SPD)

17.3 Organization of National Command Authority (NCA) 
